\title{
Successful chemical cholecystectomy: a laparoscopic guided technique
}

\author{
A CUSCHIERI, A A B ABD EL GHANY, AND M P HOLLEY \\ From the Departments of Surgery and Pathology, Ninewells Hospital and Medical School University of \\ Dundee, Scotland
}

\begin{abstract}
summary A laparoscopic guided technique of percutaneous chemical destruction of the gall bladder is described. The procedure entails the creation of a percutaneous access cholecystostomy for stone removal/fragmentation. After endoscopic occlusion of the cystic duct, the alkali corrosive, sodium carbonate was instilled into the gall bladder for 10-15 minutes. The treatment was applied in 11 animals with three deaths because of technical mishaps and eight survivors, in five of which a histologically confirmed complete destruction of the gall bladder (chemical cholecystectomy) was achieved without damage to the rest of the biliary tract or liver parenchyma.
\end{abstract}

During the past decade newer treatment modalities have been introduced as alternatives to cholecystectomy for gall stones. The efficacy of some - for example, gall stone dissolution by oral bile salt therapy ${ }^{1-3}$ and methyl tert butyl ether instilled directly into the gall bladder through a percutaneous cholecystostomy, is undoubted. More recently extracorporeal shock wave lithotripsy using second generation equipment with a special transducer has resulted in a stone clearance rate for solitary gall stones in a functioning gall bladder of $80 \%$ at one year. ${ }^{-7}$ The limitation which is common to all these newer forms of treatment is the high recurrence rate even with maintenance oral bile salt therapy." The consensus view is that longterm therapy of this nature is therefore ineffective and inadvisable because of the risk of hepatotoxicity and the endogenous production of bile salt derivatives which are known to be carcinogenic." "1"

To ensure against stone recurrence, dissolution or fragmentation of gall stones would have to be followed by obliteration of the gall bladder reservoir in lieu of surgical cholecystectomy. The present experiments were designed with a view to developing a technique which would allow gall stone

\footnotetext{
Address for correspondence: Prof $\lambda$ Cuschicri, Dept of Surgery. Ninewells Hospital and Medical School. Dundec DDI YSY.

Accepted for publication 4 April lose
}

fragmentation/removal and safe chemical destruction of the gall bladder.

\section{Methods}

ANIMALS

All the experiments were conducted in Large White/ Landrace cross pigs in view of the close similarity of the extrahepatic biliary tract of this species to that of man. The model was set up in pigs shortly after weaning (average weight $20 \cdot 0 \mathrm{~kg}$ ).

\section{LAPAROSCOPIC PERCUTANEOUS \\ CHOLECYSTOSTOMY}

The procedure was performed under general anaesthesia with halothane and endotracheal intubation using a rebreathing circuit incorporating a $\mathrm{CO}_{2}$ absorber. The minilaparoscopy instruments used for percutaneous cholecystostomy were developed by Karl Storz (Tuttlingen, West Germany). After the induction of a pneumoperitoneum with a Veress needle and air insufflation, the $5 \mathrm{~mm}$ trocar/cannula was inserted through a small stab incision at the midpoint of the linea alba. Initially the liver and gall bladder were inspected with a forward/oblique $30^{\circ}$ telescope. A $4 \mathrm{~mm}$ accessory trocar/cannula (for insertion of the palpating probe) was introduced through a small stab incision in the right flank. Under laparoscopic visual guidance, a stainless steel 


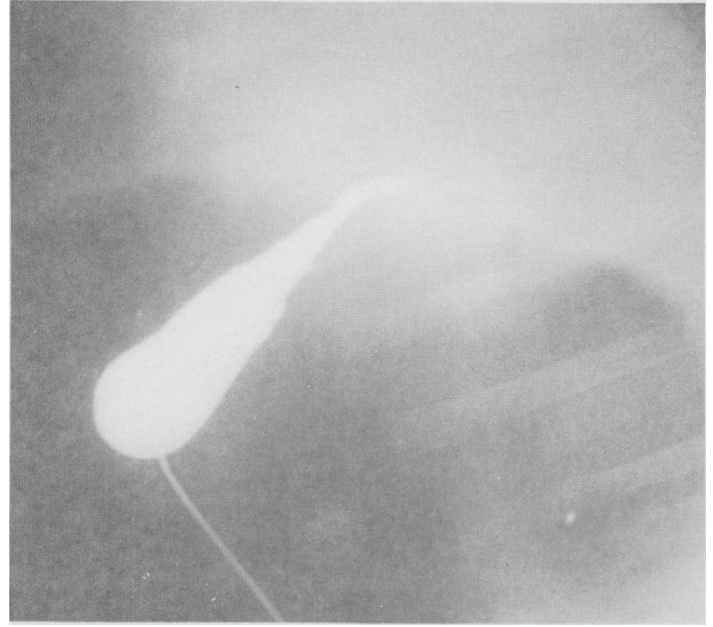

Fig. 1 Cholecystogram after the creation of a percutaneous laparoscopic cholecystostomy.

stilette was introduced percutaneously through the right subcostal region at a point which was ascertained by the viewing telescope to be nearest to the fundus of the gall bladder. This stilette was used to

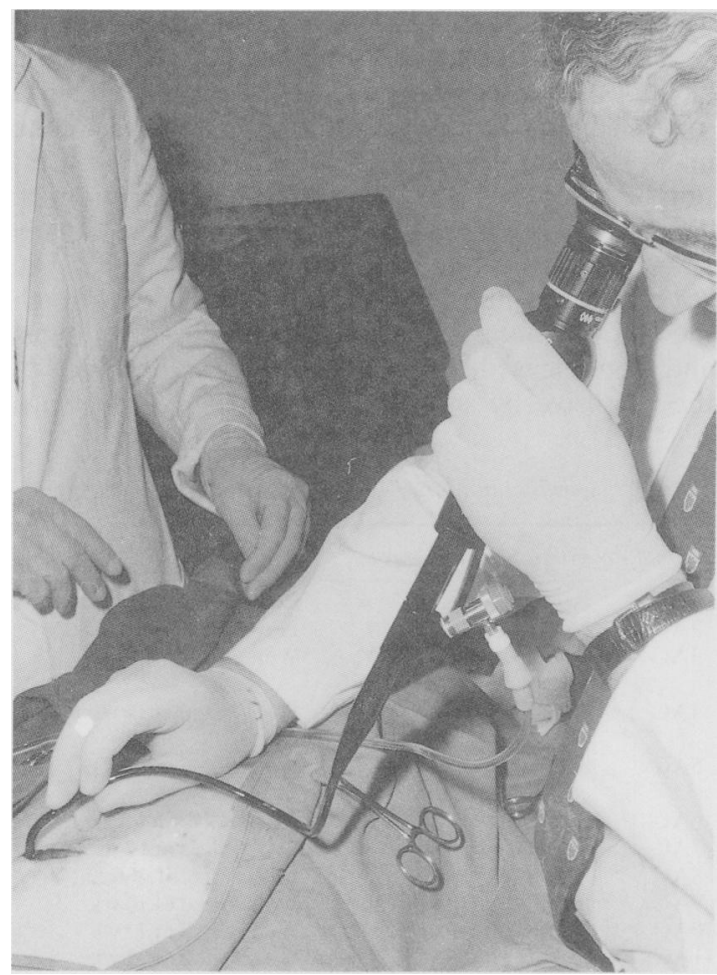

Fig. 2 Insertion of the flexible choledochoscope into the gall bladder via the matured and dilated cholecystostomy tract. puncture the gall bladder fundus. A silicone balloon tipped catheter (F8) was then introduced over a guide wire into the gall bladder lumen and its selfretaining balloon inflated with $3.0 \mathrm{ml}$ saline. Accurate location of the catheter and balloon in the gall bladder lumen was checked by laparoscopic inspection and injection of $20 \%$ Hypaque ( $\mathrm{Na}$ diatrizoate) through the catheter (Fig. 1). The catheter was then pulled to approximate the gall bladder to the abdominal wall and thereby achicve a short straight tract. After desufflation of the peritoneal cavity, the cannulac were removed and the stab wounds sutured. The external part of the cholecystostomy tube was then tunnelled subcutaneously to the back of the animal, its end spigoted and then covered with a povidone iodine dressing. A tube cholecystocholangiogram was repeated three days later using $5,15,25 \mathrm{ml}$ sodium diatrizoate.

After maturation for 10-14 days, the cholecystostomy catheter was removed and the tract dilated to F14 using plastic and balloon dilators. This procedure was performed under sedation of the animal with intramuscular 4\% azaperone (Suicalm). When dilated, the tract allowed the insertion of both the Olympus OES CHF-P10 flexible choledochoscope (Fig. 2) and the Berci-Shore rigid endoscope (Karl Storz, Tuttlingen).

HUMAN STONE INSIERTION

Both cholesterol and pigment stones obtained from human cholecystectomy specimens were introduced

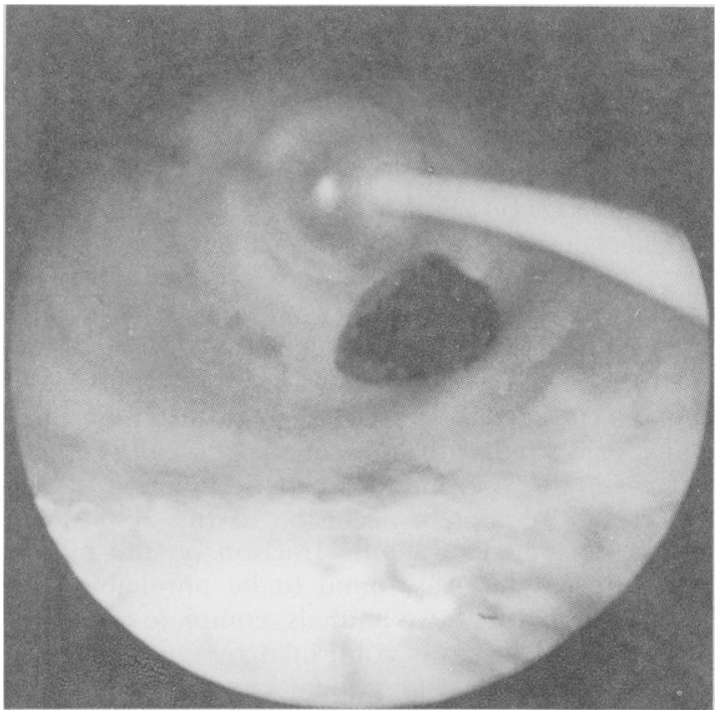

Fig. 3 Endoscopic view of human cholesterol stone in the porcine gall bladder. 


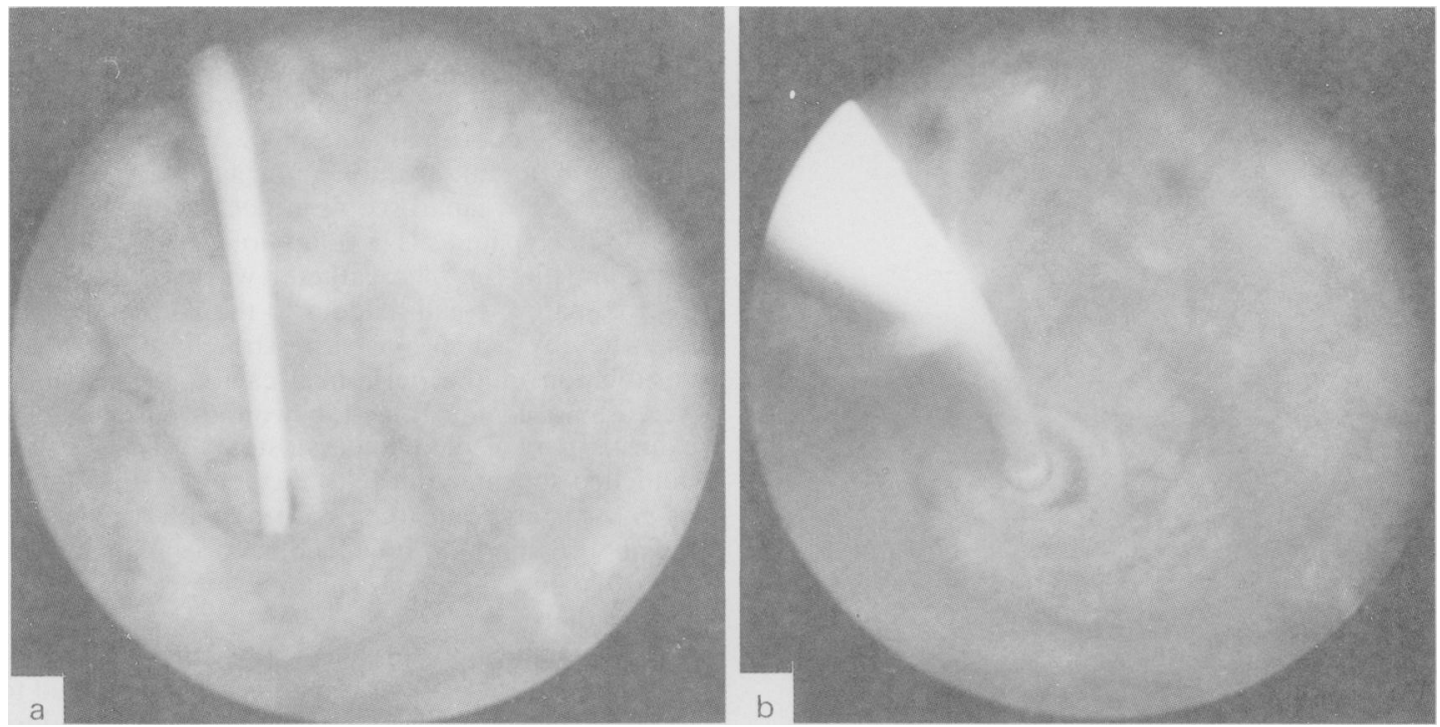

Fig. 4 Endoscopic view of biliary balloon catheter in the cystic duct (a) before and (b) after inflation of the balloon.

through the dilated access cholecystostomy. The stones were weighed, measured and then sterilised by immersion in $75 \%$ ethanol. Thereafter they were pushed into the gall bladder. Stones smaller than $3 \cdot 0$ $\mathrm{mm}$ were observed to migrate into the common duct. Stones exceeding this diameter were used subsequently for stone growth and lithotripsy studies (Fig. 3 ). Growth of human stones due to surface deposition of calcium bilirubinate was observed in all animals. Details of the data obtained from the stone growth experiments are being reported elsewhere. In four animals with human cholelithiasis, fragmentation of the stones was achieved by electrohydraulic pulses (discharge energy $0.90 \mathrm{Ws}$, frequency $2.5 \mathrm{sec}$ to $6 \mathrm{~Hz}$ ) generated by the Calcutript lithotriptor (Model 27080 B/C/D, Karl Storz, Tuttlingen) before chemical destruction of the gall bladder.

\section{CHEMICAL CHOLECYSTECTOMY}

The gall bladder was first inspected by means of the flexible or rigid choledochoscope and a biliary balloon catheter was inserted into the cystic duct under vision and its balloon inflated with air (Fig. 4). In the initial experiments adequate inflation of the balloon and complete occlusion of the cystic duct were ascertained by gentle traction on the biliary catheter. As this was found to be unreliable and resulted in death of two animals, complete occlusion of the cystic duct was confirmed by contrast cholangiography in the subsequent experiments. After withdrawal of the choledochoscope, an F 10-12 Foley catheter was inserted into the gall bladder, its balloon inflated and traction applied to occlude the cholecystostomy exit tract. The volume of saline required to fill the porcine gall bladder with the Foley catheter in situ averaged $15 \mathrm{ml}$. After initial testing with alcohol $(75 \%)$ and phenol $(5,40 \%)$ which gave inconsistent results, $10-15 \mathrm{ml}$ aqueous solution of the alkali corrosive, $\mathrm{Na}_{2} \mathrm{CO}_{3}$ were used in a concentration of $0.33 \mathrm{~g} / \mathrm{ml}$ and a contact time of $10-15$ minutes. This alkali corrosive was selected because of its low $\mathrm{LD}_{50}{ }^{12}$ after oral administration in animals. The sclerosant was injected into the gall bladder through the Foley catheter which was clamped for 15 minutes and then released. The gall bladder was evacuated of the corrosive by syringe suction and washed twice

Table 1 Clinical outcome after chemical cholecystectomy

\begin{tabular}{|c|c|c|}
\hline Animal & Follow up radiology & Outeome \\
\hline $\mathrm{AAC}$ & No GB lumen at 12 wk & Well, killed at $12 \mathrm{wk}$ \\
\hline $2 \mathrm{AC}$ & Not done & Peritonitis, killed at $48 \mathrm{~h}$ \\
\hline $3 \mathrm{AC}$ & $\begin{array}{l}80 \% \text { reduction of } \mathrm{GB} \\
\text { volume at } 12 \mathrm{wk}\end{array}$ & Well. killed at $12 \mathrm{wk}$ \\
\hline$+\mathrm{AC}$ & $\begin{array}{l}90 \% \text { reduction of } \mathrm{GB} \\
\text { volume at } 10 \mathrm{wk}\end{array}$ & Well. killed at $10 \mathrm{wk}$ \\
\hline SAC & $\begin{array}{l}80 \% \text { reduction of } \mathrm{GB} \\
\text { volume at } 10 \mathrm{wk}\end{array}$ & Well, killed at $10 \mathrm{wk}$ \\
\hline GAC & Not done & Died of liver failure at $+w k$ \\
\hline $7 \mathrm{AC}$ & No GB lumen at 10 wk & Well. killed at 12 wk \\
\hline $\mathrm{SAC}$ & Not done & Died of liver failure at $48 \mathrm{~h}$ \\
\hline $9 \wedge \mathrm{C}$ & No GB lumen at 14 wk & Well. killed at $16 \mathrm{wk}$ \\
\hline $10 \mathrm{AC}$ & No GB lumen at $12 \mathrm{wk}$ & Well, killed at 12 wk \\
\hline $11 \mathrm{AC}$ & No GB lumen at $12 \mathrm{wk}$ & Well. killed at $12 \mathrm{wk}$ \\
\hline
\end{tabular}

(iB $=$ gall bladder. 

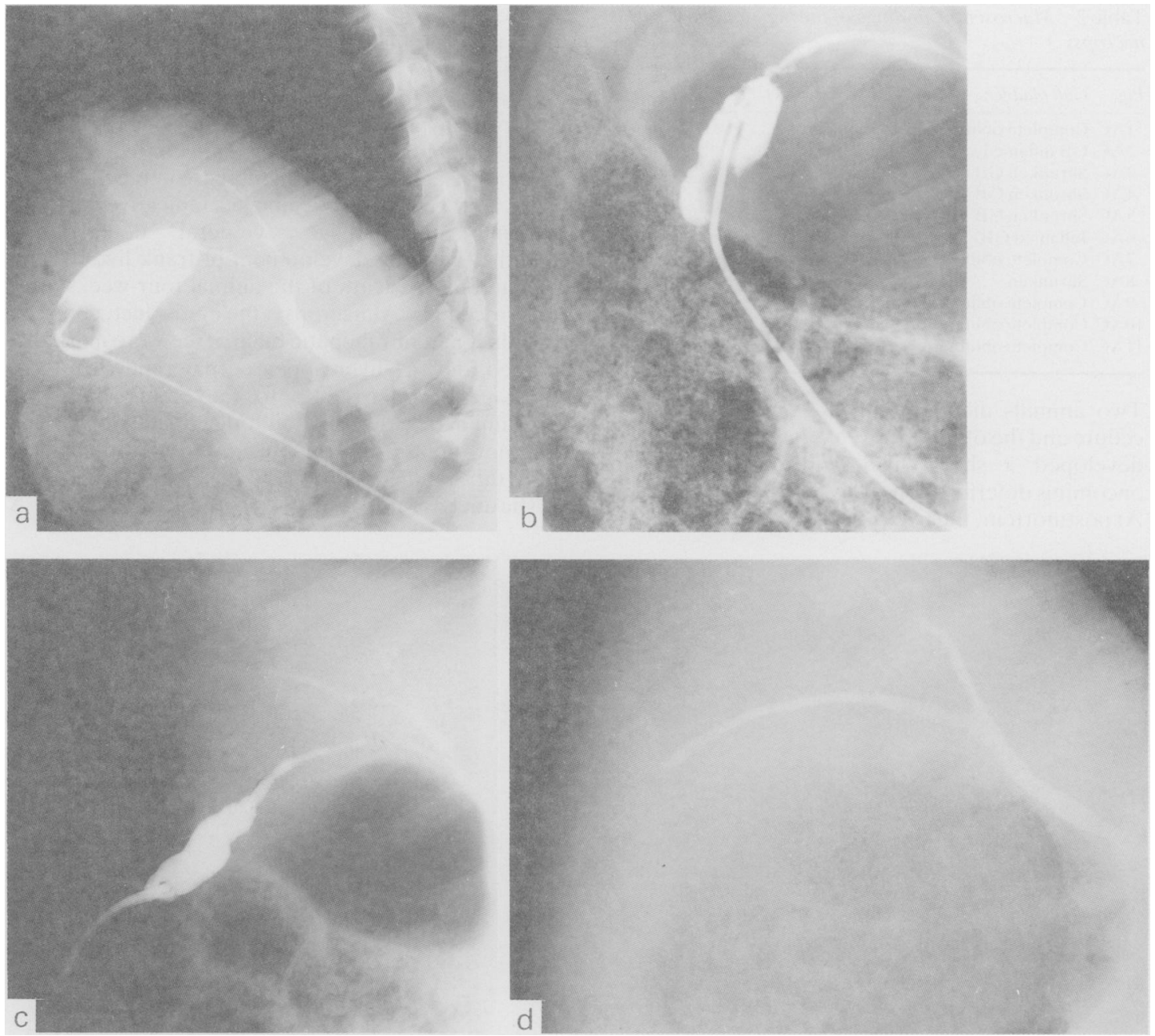

Fig. 5 Contrast radiological changes in the porcine gall bladder after instillation of $15 \mathrm{ml}$ sodium carbonate with a contact time of 15 minutes: (a) before instillation of alkaline corrosive, (b) 2 weeks later, (c) 6 weeks after, (d) 12 weeks after, before death.

with $50 \mathrm{ml}$ of isotonic saline. Its lumen was inspected by the choledochoscope to ensure against perforation. After deflation of the balloon, the biliary catheter was withdrawn from the cystic duct. The Foley catheter was then reinserted into the gall bladder without inflation of the balloon and the external portion tunnelled subcutaneously. Progress of the lesion was by serial tube cholecystocholangiograms, clinical assessment and liver function tests. A postmortem examination was performed in all the animals at the time of death or sacrifice (12-16 weeks after the chemically induced gall bladder lesion). At postmortem, the entire extrahepatic biliary tract was dissected and removed together with multiple liver biopsies. The specimens were fixed in formalin for detailed histological examination by a pathologist (MPH) who was not aware of the experimental details. Control specimens were obtained from untreated pigs of the same age and weight.

\section{Results}

The standardised sodium carbonate gall bladder injury was inflicted in 11 animals. The duration of the procedure, including the preliminary endoscopy and occlusion of the cystic duct, averaged 30 minutes. 
Table 2 Macroscopic findings of the hepatobiliary tract at necropsy

\begin{tabular}{|c|c|c|c|}
\hline Pig & (iall bladder & E $H$ biliary tract & liver \\
\hline $1 \mathrm{AC}$ & Complete obliteration & Normal & Normal \\
\hline $2 \mathrm{AC}$ & ( $\mathrm{iB}$ inflamed & Rupture (BD) & Normal \\
\hline $3 A C$ & Shrunken ( $\mathrm{iB}$ & Normal & Normal \\
\hline$+A C$ & Shrunken (iB & Normal & Normal \\
\hline $5 \mathrm{AC}$ & Shrunken (iB & Normal & Normal \\
\hline GAC & Inflamed ( & Dilatation and cholangitis & Abnormal \\
\hline $7 \mathrm{AC}$ & Complete obliteration & Normal & Normal \\
\hline $\mathrm{SAC}$ & Shrunken & Dilatation and cholangitis & Abnormal \\
\hline $9 \mathrm{AC}$ & complete obliteration & Normal & Normal \\
\hline $10 \mathrm{AC}$ & Complete obliteration & Normal & Normal \\
\hline $11 \mathrm{AC}$ & complete obliteration & Normal & Normal \\
\hline
\end{tabular}

Two animals died, one at 48 hours after the procedure and the other four weeks later. The former pig developed a shock like syndrome with rapidly oncoming deterioration of liver function and coma. At postmortem, the liver was pale with multiple areas of gross necrosis. In this animal, the biliary balloon used to block the cystic duct had burst with entry of the sclerosant into the biliary tract. The second animal developed a progressive illness accompanied by fever, hyperbilirubinaemia and severe anaemia. The haematological picture showed hypochromic microcytic anacmia with an increase in the nucleated cells, spur cells and reticulocytes indicative of occult internal haemorrhage. General deterioration together with the development of frank liver failure resulted in the death of the animal four weeks after the procedure. At necropsy, the cystic duct, common bile duct and intrahepatic biliary tree were markedly dilated and the liver appeared pale and shrunken. Leakage of sclerosant into the biliary tract was presumed to be the cause although the biliary balloon had not burst in this animal. A presclerosant injection tube cholecystogram to test occlusion of the cystic duct was not performed in these two animals. A

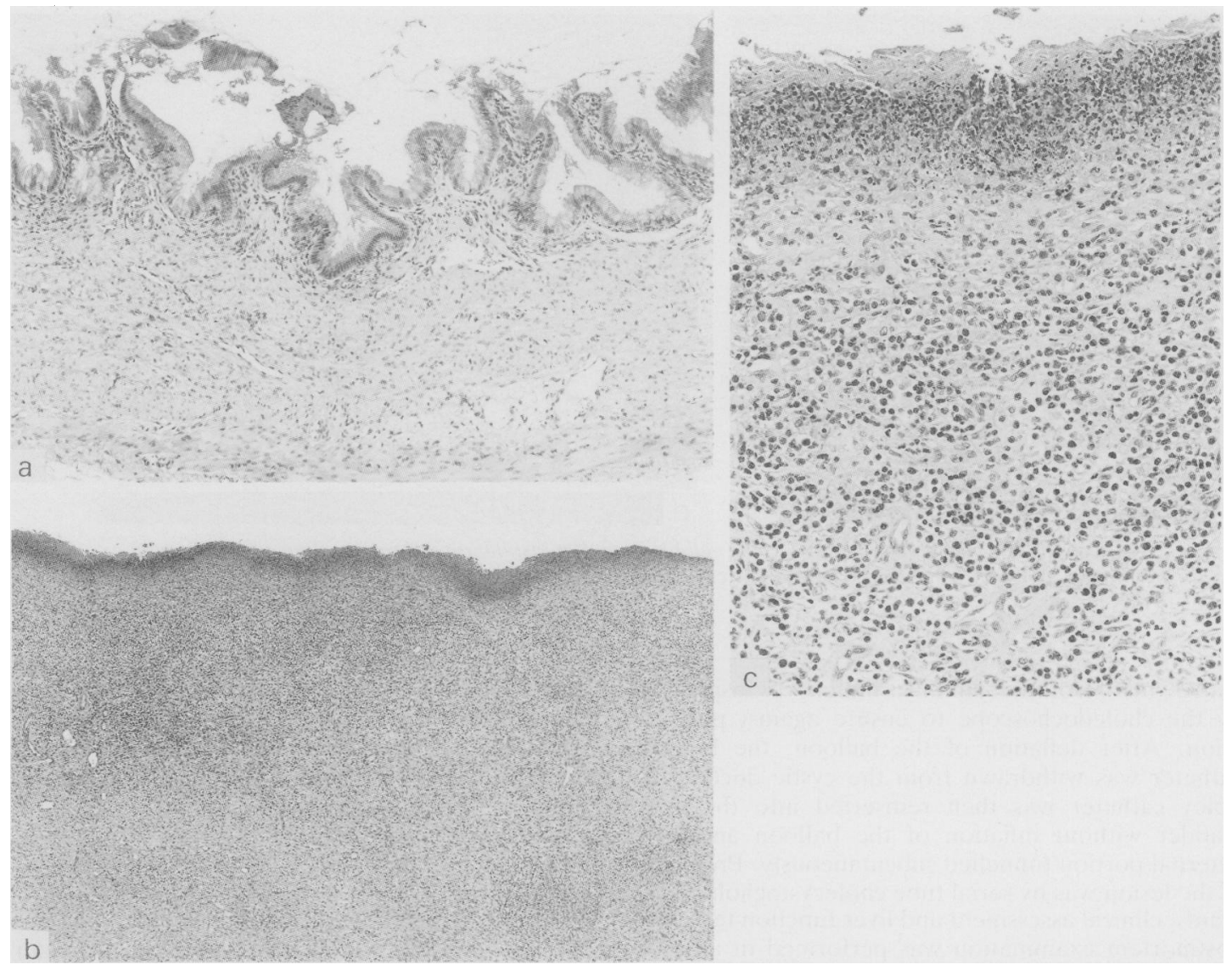

Fig. 6 (a) Low power view of untreated porcine gall bladder wall. (b) Low power view of gall bladder showing total transmural necrosis with replacement by granulation tissue. (c) High power view showing acute on chronic inflammation within the granulation tissue. 


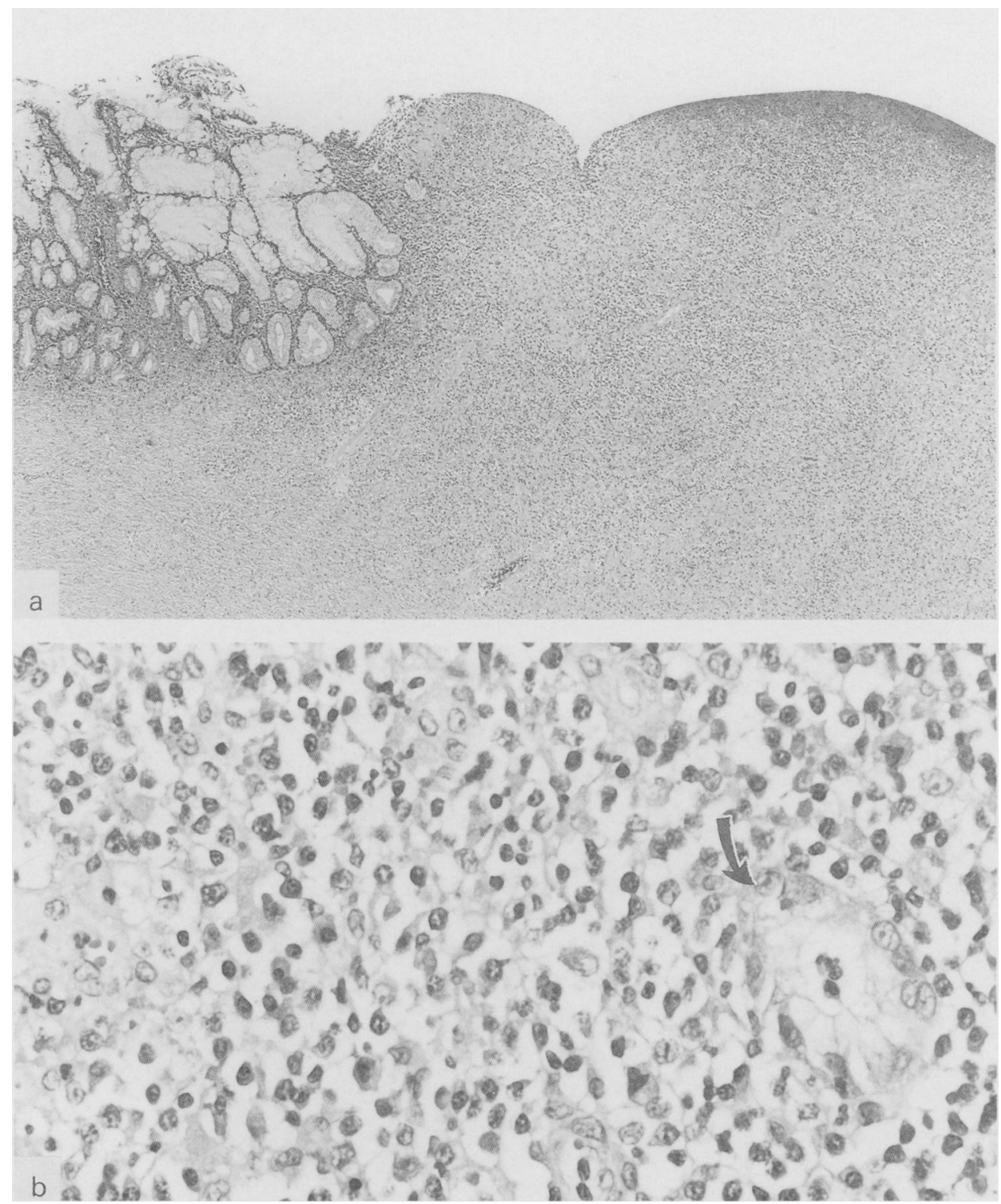

Fig. 7 (a) Incomplete destruction of the gall bladder with surviving mucosa adjacent to areas of complete transmural necrosis.

(b) Near complete destruction but a surviving mucosal gland (arrowed) is seen in the granulation tissue.

third pig developed generalised peritonitis 48 hours after the procedure and was destroyed. At necropsy, a complete tear of the common bile duct with generalised biliary peritonitis was found. This had been caused by overinflation of the balloon of the biliary catheter used to block the cystic duct. The other eight animals (Table 1) remained well with normal liver function tests and blood picture until the time of death.

RADIOLOGICAI. CHANGES

A progressive shrinkage of the gall bladder lumen was observed in all the surviving animals with complete obliteration in five within 12-16 weeks of 

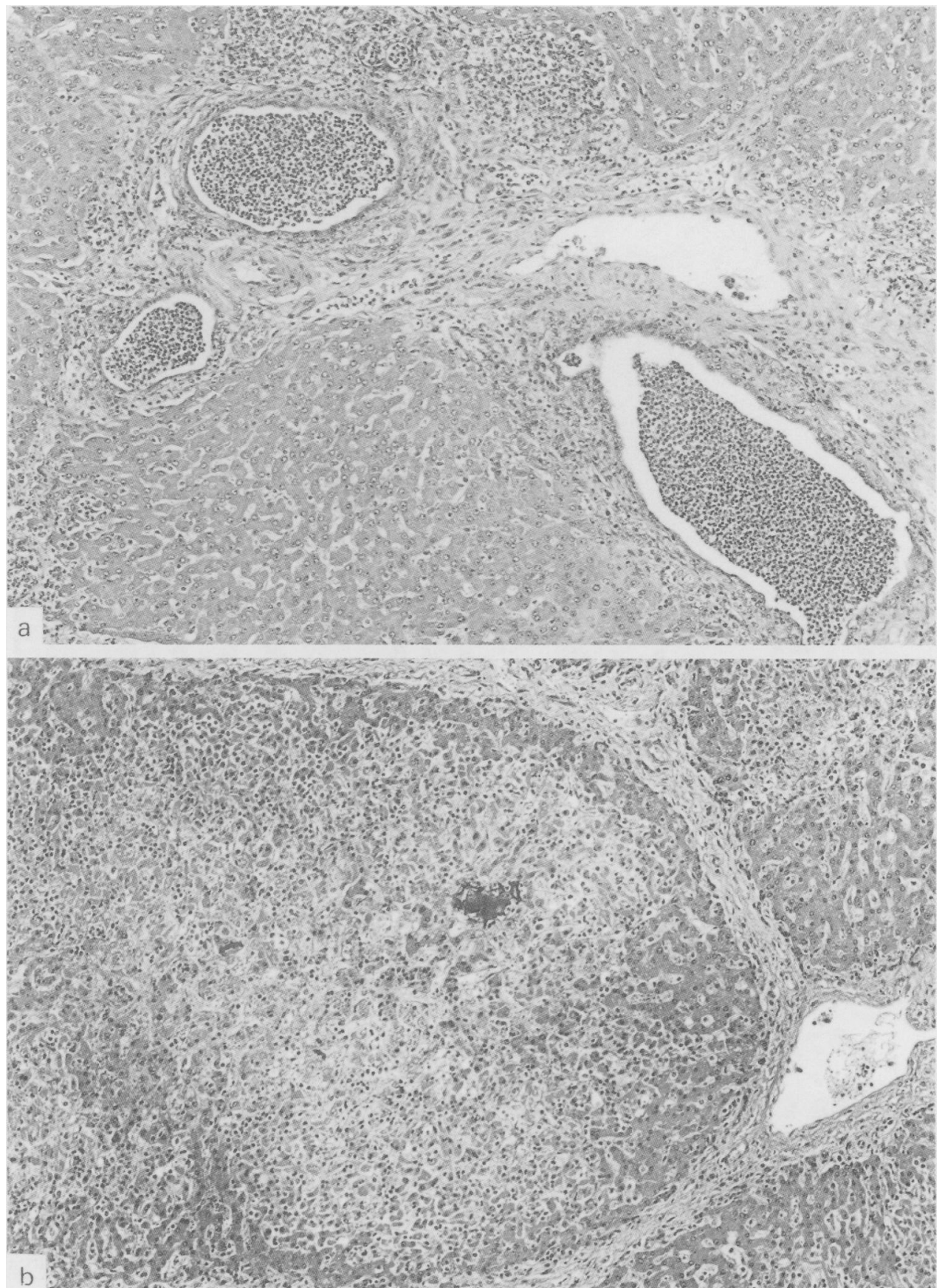

Fig. 8 (a) Liver biopsy showing severe cholangitis with numerous polymorphs in the intrahepatic biliary tree, marked inflammation of the portal tracts and necrosis of the adjacent hepatic parenchyma. (b) Widespread cholangitis with inflammation of the portal tracts, centrilobular necrosis and marked bile stasis. 
the chemically induced gall bladder injury (Fig. 5). All the animals in which a complete obliteration of the gall bladder lumen was achieved had been treated with $15 \mathrm{ml} \mathrm{Na}_{2} \mathrm{CO}_{3}$ and a contact time of 15 minutes. The biliary tract (intra and extrahepatic) was radiologically normal just before death in all the surviving animals.

\section{GROSS ANATOMICAL CHANGES}

The macroscopic findings at necropsy confirmed the above radiological contrast studies (Table 2). The gall bladder had been replaced by a fibrous mass in five animals and was considerably thickened with a markedly reduced lumen in three. A tight stricture at the origin of the cystic duct was present in three animals. The rest of the extrahepatic biliary tract and liver showed normal appearances in the eight surviving animals. Dilatation and inflammation of the extrahepatic biliary tract were present in the two animals which died after instillation of the sclerosant. The liver of these animals was pale and necrotic.

Aside from a few adhesions between omentum and or small bowel with the gall bladder scar, no other abnormality within the peritoneal cavity was encountered in the surviving animals.

\section{HISTOLOGICAL CHANGES}

Total transmural necrosis of the entire gall bladder with replacement by granulation tissue (Fig. 6) showing acute or chronic inflammation was present in five animals. In the other three animals although there was extensive transmural necrosis with granulation tissue formation, surviving areas of gall bladder mucosa were observed (Fig. 7). Lymphoid aggregates were prominent in many of the specimens from the gall bladder and cystic ducts of the treated animals.

The cystic duct showed fibrosis and acute on chronic inflammation especially marked near its origin in all the surviving animals. The common hepatic and the common bile ducts were considered normal when compared with the control specimens.

The histological examination of all the liver biopsies obtained from the surviving animals was normal. The liver histology of the pig which succumbed at 48 hours showed very severe cholangitis, the intrahepatic bile ducts being full of polymorphs in addition to extensive severe inflammation of the portal tracts with areas of necrosis of the adjacent liver parenchyma (Fig. 8a). Similar histological appearances were encountered in the animal which died at four weeks: widespread cholangitis and inflammation of the portal tracts together with centrilobular necrosis and considerable bile stasis (Fig. $8 b)$.

\section{Discussion}

The findings of this study indicate that safe chemical destruction of the gall bladder through a percutaneous cholecystostomy is feasible. The technique used in these experiments is certainly applicable to man and subsequent to further animal studies to ensure maximum safety, the technique may prove useful in the treatment of gall stone disease as an alternative to surgical cholecystectomy especially in poor risk patients. We have used laparoscopic percutaneous cholecystostomy in poor risk patients with acute cholecystitis or severe jaundice due to distal large bile duct obstruction ${ }^{1314}$ and a similar ultrasound/computed tomography guided procedure is practised in several centres..$^{15-17}$

The procedure used in these experiments is particularly attractive because it allows stone fragmentation/dissolution/removal followed by chemical destruction of the gall bladder to prevent stone recurrence and thus overcome the disadvantage of all the methods of non-operative treatment of gall stone disease. The temporary occlusion of the cystic duct carries the added advantage of preventing the migration of stone fragment into the common bile duct during or after successful lithotripsy.

There are, however, existing problems which preclude use of the technique in human subjects at present. Balloon occlusion of the cystic duct is not completely reliable. This problem has been largely overcome by the design of a special laparoscopic cystic duct clamp (Karl Storz) which is undergoing animal testing by us at the moment. Further studies are also necessary on several other effective sclerosants/corrosives/fixatives with lower $\mathrm{LD}_{50}$ and better therapeutic margin than sodium carbonate. Longterm studies are also needed to exclude the possibility of cancer developing in the gall bladder scar tissue especially in the presence of small foci of surviving glandular elements. These preliminary studies have shown, however, that chemical cholecystectomy is feasible.

We are grateful for the equipment designed and manufactured by Karl Storz, Tuttlingen, West Germany and for the financial support obtained from this company.

\section{References}

1 Danzinger R, Hoffman AF, Schocnficld LJ, Thistle JL. Dissolution of cholesterol stones by chenodeoxycholic acid. N Engl J Med 1972; 286: 1-8.

2 Maton PN, Iser JH, Reuben A. Saxton HM, Murphy GM. Dowling RH. Outcome of chenodeoxycholic acid (CDCA) treatment in 125 patients with radiolucent gallstones. Medicine 1982; 61: 85-96. 
3 Bachrach WH, Hoffman AF. Ursodeoxycholic acid in the treatment of cholesterol cholelithiasis. Dig Dis Sci 1982; 27: 833-6.

4 Allen MJ, Borody TJ, Bugliosi TF, May GR, LaRusso NF. Rapid dissolution of gallstones by methyl tert-butyl cther. Preliminary obscrvations. N Engl J Med 1985; 312: $217-20$.

5 Sauerbruch T, Delius M, Paumgartner G, et al. Fragmentation of gallstones by extracorporeal shock waves. N Engl J Med 1986; 314: 818-22.

6 Saucrbruch T, Holl J, Weber W, et al. Extracorporeal shock wave lithotripsy of gallbladder stones: results of 101 treatments [Abstract]. Gastroenterology 1987; 92: 1608 .

7 Staritz M, Floth A, Buess G, et al. Extracorporeal shock waves (ESW) for gallstone fragmentation. First in-vitroexperience with a second generation device working without the conventional water bath [Abstract]. Gastroenterology 1987; 92: 1652.

8 Marks JW, Lan S-P, the Steering Committee and the National Cooperative Gallstone Groups. Low dose chendiol to prevent gallstone recurrence after dissolution therapy. Ann Intern Med 1984; 100: 37681.

9 Bouchier IAD. Non-surgical treatment of gallstones: many contenders but who will win the crown. Gut 1988; 29: $137-42$.

10 Owen RW, Thompson MH, Hill MJ. Wilpart M. Mainguet $P$. Roberfroid $M$. The importance of the ratio of lithocholic to deoxycholic acid in large bowel carcinogenesis. Nutr Cancer 1987; 9: 67-71.

11 Irving AD. Carcinoma of the gallbladder in a patient on long term chenodeoxycholic acid therapy. Clin Oncol $1981 ; 7: 245-8$.

12 Dreisbach RH. Handbook of poisoning. California: Langr Medical Publications, 1980: 192-207.

13 Cuschieri A. Laparoscopy in general surgery and gastroenterology. Br J Hosp Med 1980; 24: 252-8.

14 Berci G, Cuschicri A. Practical laparoscopy. London: Baillićre Tindall, 1986.

15 Pearse DM, Hawkins IF, Shaver R, Vogel S. Percutancous cholecystostomy in acute cholecystitis and common duct obstruction. Radiology 1984; 152: 365-7.

16 Burhenne HJ, Stoller JL. Minicholecystostomy and radiologic stone extraction in high-risk cholclithiasis paticnts. Am J Surg 1985; 149: 632-5.

17 Min-Huo Hwang. Lein-Ray Mo, Gim-Der Chen, JyhChung Yang, Chanson Lin, Sheng-Kao Yuch. Percutancous transhepatic cholecystic lithotripsy. (jastrointest Endosc 1987; 33: 301-3. 